\title{
Enzymatic Modification for Ascorbic Acid and Alpha-Tocopherol to Enhance their Stability in Food and Nutritional Applications
}

\author{
Pamela Torres, Adinarayana Kunamneni, Antonio Ballesteros and Francisco J. Plou* \\ Departamento de Biocatálisis, Instituto de Catálisis y Petroleoquímica, CSIC, Cantoblanco, 28049 Madrid, Spain
}

\begin{abstract}
Antioxidants protect cells against the effects of harmful free radicals and play an important role in preventing many human diseases (e.g. cancer, atherosclerosis, neurodegeneration, inflammatory disorders, etc.) and aging itself. In addition, antioxidant molecules are employed to prevent unsaturated oil products from becoming rancid during storage and thus extend oil life. The modification -chemical or enzymatic- of natural antioxidants in order to increase their miscibility and/or stability towards the action of light and/or oxygen renders a series of "semisynthetic" antioxidants with great impact in the food and feed industries. In this review, we will discuss the enzymatic modifications of antioxidant vitamins $\mathrm{C}$ and E. L-Ascorbic acid (vitamin C) is the major water-soluble natural antioxidant acting as a free radical scavenger, and plays an important role in regenerating vitamin E. However, due to the low miscibility of ascorbic acid with $\alpha$-tocopherol, it is necessary to use ascorbyl fatty acid derivatives. Thus, esters of L-ascorbic acid with long-chain fatty acids (esp. palmitic or stearic) are employed as additives (E-304) in foods rich in lipids. The enzymatic synthesis of acyl L-ascorbates offers some advantages compared with the current chemical process, such as its high regioselectivity and the moderate reaction conditions. Vitamin E enhances the oxidative stability of polyunsaturated fatty acids from peroxidation acting as a free radical scavenger and is generally administered in the form of all-rac- $\alpha$-tocopheryl acetate or succinate to increase its stability. Several approaches have been described for the enzyme-catalysed synthesis of vitamin E acetate, based on the transesterification of vinyl acetate with vitamin $\mathrm{E}$, or the regioselective hydrolysis of $\alpha$-isophorone followed by reaction with isophytol. The above vitamin $\mathrm{C}$ and $\mathrm{E}$ derivatives may have impact not only as food preservatives but also as components of functional foods.
\end{abstract}

\section{ANTIOXIDANTS IN HEALTH AND FOOD}

Free radicals (e.g. superoxide, nitric oxide, hydroxyl radicals) and other reactive species (e.g. hydrogen peroxide, peroxynitrite hypochlorous acid) are produced in the body, primarily as a result of aerobic metabolism, causing the socalled oxidative stress. Oxidative inhibitors -called antioxidants- (e.g. glutathione, arginine, citrulline, taurine, creatine, selenium, zinc, vitamin $\mathrm{E}$, vitamin $\mathrm{C}$, vitamin $\mathrm{A}$, tea polyphenols) and antioxidant enzymes (e.g. superoxide dismutase, catalase, glutathione reductase and glutathione peroxidases) exert synergistic actions in reducing free-radical lipid oxidation. Over the past three decades there has been growing evidence showing that malnutrition (e.g. dietary deficiencies of protein, selenium, or zinc) or excess of certain nutrients (e.g. iron, vitamin $\mathrm{C}$, selenium) gives rise to the oxidation of biomolecules and cell injury [1].

Antioxidants are substances that when present at low concentration compared to that of an oxidable substrate markedly delay or prevent its oxidation. Antioxidants protect cells against the effects of harmful free radicals. There exists scientific evidence that the excessive production of free radicals in the organism, and the imbalance between their concentration and the antioxidant defenses, may be related to processes such as aging [2] and several diseases such as cancer [3,4], atherosclerosis [5], stroke [6], rheumatoid arthritis [7], neurodegeneration [8], inflammatory disorders [9] or diabetes [10]. The study of antioxidants is of great interest for the role they play in protecting living systems against

*Address correspondence to this author at the Departamento de Biocatálisis, Instituto de Catálisis y Petroleoquímica, CSIC, Cantoblanco, 28049 Madrid, Spain; E-mail: fplou@icp.csic.es lipid peroxidation and other anomalous molecular modifications [11]. The mechanisms that are involved include decompositions of peroxides, singlet oxygen inhibition and free-radical acceptors. Efficient suppression of lipid peroxidation is possible only by the concerted action of a chainbreaking antioxidant and a glutathione peroxidase. Depending on the type of lipid and biological compartment, different types of glutathione peroxidases could be involved in the suppression of these radical chain reactions. The reaction principle could also be similarly relevant for the control of inflammation-associated oxidative burst, for the maintenance of integrity of membrane lipids, as well as for the prevention of atherogenesis.

Most antioxidants are common food components, and have been used in the diet for thousands of years. Natural antioxidants can be classified in two groups: (i) those whose ingestion is essential in human feed -nutrients- comprising vitamins $\mathrm{C}$ and $\mathrm{E}$ and vitamin precursors (carotenoids); (ii) plant-derived compounds of low molecular weight, basically polyphenols (e.g. flavonoids), which have not been demonstrated to be essential for health . In last years, consumers have been increasingly confronted with the so-called functional food products, first introduced in Japan, which are claimed to promote health and well-being beyond their nutritive properties $[12,13]$.

Fats, oils and lipid-based foods deteriorate through several degradation reactions both on heating and on long-term storage [14]. The main deterioration processes are oxidation reactions that result in decreased nutritional value and sensorial quality. The spontaneous reaction of atmospheric oxygen with lipids, known as autooxidation, is the most common process leading to oxidative deterioration (Fig. 1) [15]. In 
addition to the prevention of oxygen access, the use of low temperatures, the inactivation of enzymes causing oxidation, or a suitable packaging, oxidation may be also inhibited by the use of specific additives (antioxidants) that may vary in their chemical structure and mode of action. Antioxidant molecules prevent unsaturated oil products from becoming rancid during storage, thus extending its shelf life [16,17]. Antioxidants were first used for food preservation before World War II. The most commonly used antioxidants for food preservation are listed in Table $\mathbf{1}$.

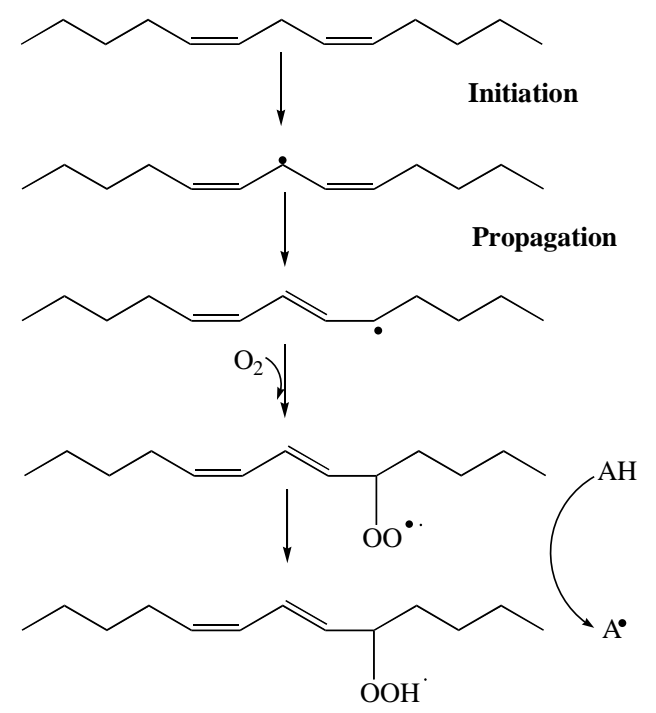

Fig. (1). Antioxidant $(\mathrm{AH})$ action in the phases of lipid peroxidation.

Table 1. Antioxidants Most Commonly Used in Foods

\begin{tabular}{|l|l|}
\hline Antioxidant & EC number \\
\hline \hline L-Ascorbic acid & E300 \\
\hline Sodium L-ascorbate & E301 \\
\hline Calcium L-ascorbate & E302 \\
\hline Potassium L-ascorbate & E303 \\
\hline $\begin{array}{l}\text { Fatty acid esters of ascorbic acid esters } \\
\text { I. Ascorbyl palmitate } \\
\text { II. Ascorbyl stearate }\end{array}$ & E304 \\
\hline Mixed tocopherols concentrate (natural) & \\
\hline Alpha-tocopherol (synthetic) & E306 \\
\hline Gamma-tocopherol (synthetic) & E307 \\
\hline Delta-tocopherol (synthetic) & E308 \\
\hline Propyl gallate & E309 \\
\hline Octyl gallate & E310 \\
\hline Dodecyl gallate & E311 \\
\hline Erythorbic acid & E312 \\
\hline tert-Butylhydroquinone (TBHQ) & E315 \\
\hline Butylated hydroxyanisole (BHA) & E319 \\
\hline Butylated hydroxytoluene (BHT) & E320 \\
\hline Lecithins & E321 \\
\hline Citric acid & E322 \\
\hline L-Tartaric acid & E330 \\
\hline
\end{tabular}

The autooxidation of lipids starts with an initiation reaction during which free radicals are formed, followed by propagation reactions during which free radicals are converted into other radicals, and finally a termination reaction that involves the combination of two radicals, with the formation of stable products (Fig. 1). The most common food antioxidants (primary antioxidants) interfere with lipid autoxidation by rapid donation of hydrogen atoms to lipid radicals (Fig. 1). Alpha-tocopherol (vitamin E) suppresses the propagation of radical chain reactions at the stage of the peroxy radical.

Natural antioxidants such as vitamins $\mathrm{C}$ and $\mathrm{E}$ are the best accepted for food applications. Synthetic phenolic antioxidants, like tert-butylhydroquinone (TBHQ), butylated hydroxytoluene (BHT), butylated hydroxyanisole (BHA) and propyl gallate are not so well accepted by consumers as dietary components, and there has been growing concern over their possible side-effects.

\section{CHEMICAL AND ENZYMATIC MODIFICATIONS OF ANTIOXIDANTS}

The modification of natural antioxidants (i) to improve their chemical, oxidative or heat stability, or (ii) to alter their hydrophile-lipophile balance (HLB), yields a series of "semisynthetic" antioxidants (e.g. tocopheryl acetate, Lascorbyl palmitate) with great impact in the industry. These derivatives may have impact not only as food preservatives but also as components of functional foods.

The antioxidant derivatives are generally prepared using strongly corrosive acids such as sulfuric acid or hydrogen fluoride followed by a re-esterification step [18]. In this context, the chemical synthesis of benzoic and phenolic esters is commonly performed with acid or basic catalysts under reflux [19], but these procedures do not fulfill the requirements needed for food applications. To overcome the shortcomings of conventional processes, new approaches based on the socalled "green chemistry" are being developed.

Green chemistry is defined as the design, development, and application of chemical processes and products to reduce or eliminate the use and generation of substances hazardous to human health and the environment [20]. Biocatalytic processes fully participate in the "green chemistry" concept that was introduced in the 90's and its impact on sustainability is now well established [21]. Biocatalysts (either enzymes or whole-cells) constitute a greener alternative to traditional organic synthesis [22], offering appropriate tools for the industrial transformation of natural (e.g. antioxidants) or synthetic materials under mild reaction conditions, low energy requirements and minimising the problems of isomerisation and rearrangement [23]. In addition, biocatalysts are biodegradable and display chemo-, regio- and/or stereospecificity resulting in decreased by-product formation thus avoiding the need for functional group protection and activation. The relatively recent development of novel recombinant DNA technologies, e.g. (meta)genomics [24] and molecular directed evolution [25], are exerting a profound positive effect in the expression and production of large amounts of recombinant proteins (grams to kilograms, which means more competitive prices), with new- or tailored catalytic activities.

The enzymatic methods to modify the two major vitamin antioxidants $\mathrm{C}$ and $\mathrm{E}$ will be further reviewed. 


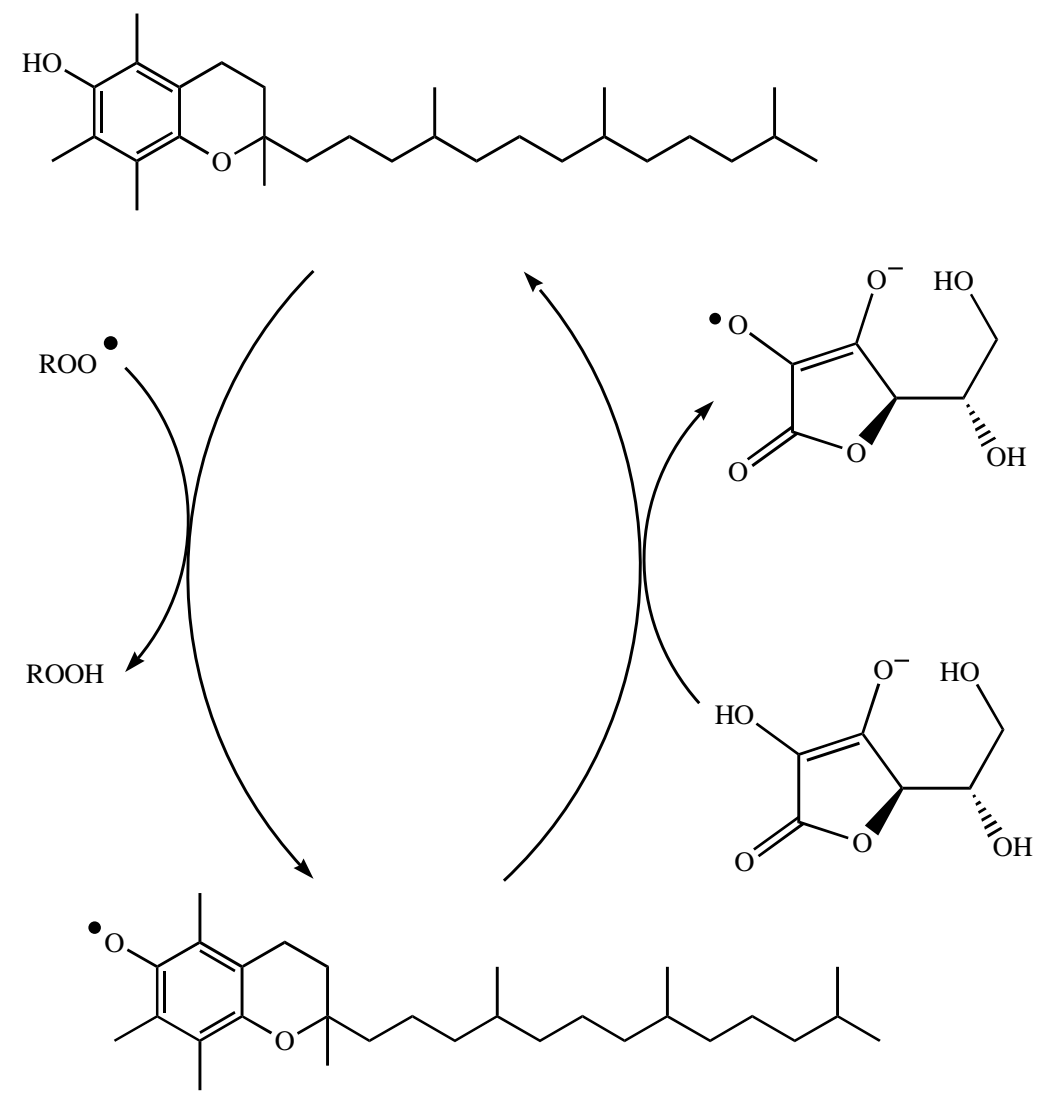

Fig. (2). Vitamin E recycling system.

\section{ENZYMATIC MODIFICATIONS OF L-ASCORBIC ACID}

L-ascorbic acid (vitamin C) belongs to the group of vitamin-based antioxidants and is the major water-soluble natural antioxidant. Acting as a free radical scavenger, Lascorbic acid and its derivatives react with oxygen, thus removing it in a closed system. The combination of L-ascorbic acid and primary antioxidants like $\alpha$-tocopherol [26,27] makes a synergic effect that results in the "vitamin E recycling system" (Fig. 2) [28]. This mixture of vitamins is usually added to cookies, pastes, meat products and other fatty products to maintain their quality and extend their shelf-life. However, due to the low miscibility of L-ascorbic acid with $\alpha$-tocopherol or with any oil-based formula, it is necessary to use ascorbyl fatty acid derivatives instead of vitamin C. It has been demonstrated that the addition of one or more hydrocarbon chains to the ascorbic acid ring, preferably in the 6-position, retains or even enhances the physiological and antioxidant activity performed by the vitamin C $[28,29]$. Thus, esters of L-ascorbic acid and long-chain fatty acids (Fig. 3) (esp. palmitic or stearic, E-304) are employed as additives for the stabilization of fats, oils and fatty products, as they retard the autooxidation of unsaturated fatty acids.

Although they are more soluble in fats than the Lascorbic acid itself, its still poor solubility in edible fats and oils and its insolubility in cold water, limit their use [30]. There are other kinds of ascorbic acid fatty acid esters, such as oleate or linoleate, which present different characteristics and could be used also as foods additives (E-304). These unsaturated fatty acids increase the miscibility with $\alpha$ tocopherol, oils or fatty products.
Nowadays, palmitate (and stearate) ascorbyl esters are produced synthetically by reacting ascorbic acid with sulphuric acid followed by re-esterification with palmitic acid (or stearic acid), and subsequently purified by recrystallization [30]. This chemical process has some clearly shortcomings such as the use of strong acids and the formation of products mixtures that need complex purification protocols [31,32].

As an alternative, the enzyme-catalysed synthesis of acyl L-ascorbates offers some advantages, such as its high regioselectivity and the moderate reaction conditions [33]. Lipases, esp. that from $C$. antarctica, have been successfully used to catalyse the enzymatic synthesis of ascorbyl derivatives employing saturated and unsaturated free fatty acids, alkyl or vinyl esters as acyl donors (Table 2) [34]. Tertiary alcohols and acetone are commonly employed as reaction media. The latter is especially appropriate as it is inexpensive, volatile and permitted for use in the manufacture of food products (directive 84-344-CEE) [35]. The use of ionic liquids as greener media for the acylation of L-ascorbic acid has been also described [36].

Fig. (4) shows the acylation progress of L-ascorbic acid with vinyl palmitate using lipase B immobilised in two different supports: the ion-exchange resin Lewatit (Novozym 435) and polypropylene (Accurel EP100) [37,38]. Experimental conditions were: $20 \mathrm{mM}$ ascorbic acid, $100 \mathrm{mM}$ vinyl palmitate, $2.5 \mathrm{mg} / \mathrm{ml}$ biocatalyst, 2-methyl-2-butanol/DMSO 95:5 (v/v), $40^{\circ} \mathrm{C}, 150 \mathrm{rpm}$. As shown, the reaction is very fast with both biocatalysts, giving approx. $90 \%$ conversion in $8 \mathrm{~h}$. Interestingly, when assaying ethyl palmitate as acyl donor under similar conditions the reaction is significantly 

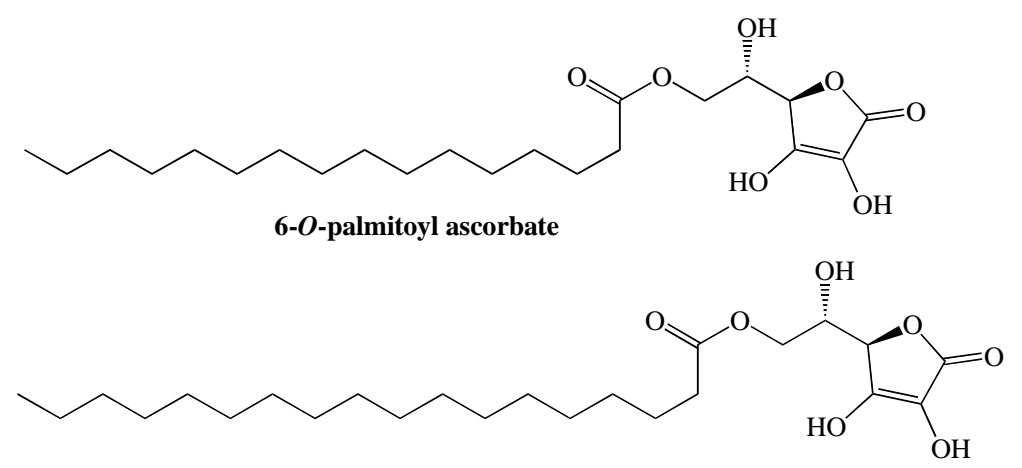

6-O-stearoyl ascorbate

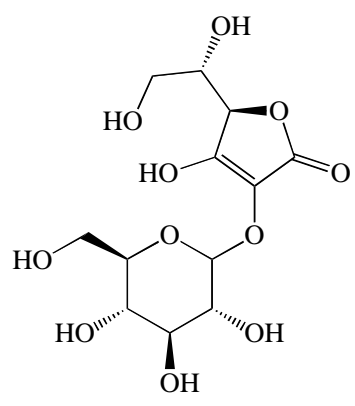

Ascorbic acid 2-glucoside

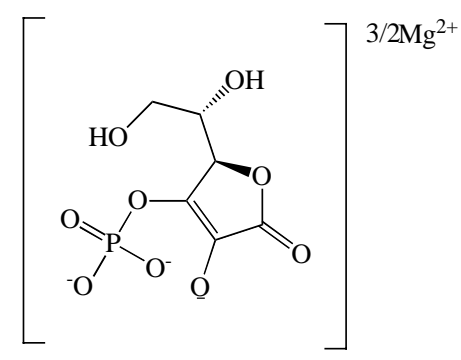

Ascorbic acid phosphate magnesium salt

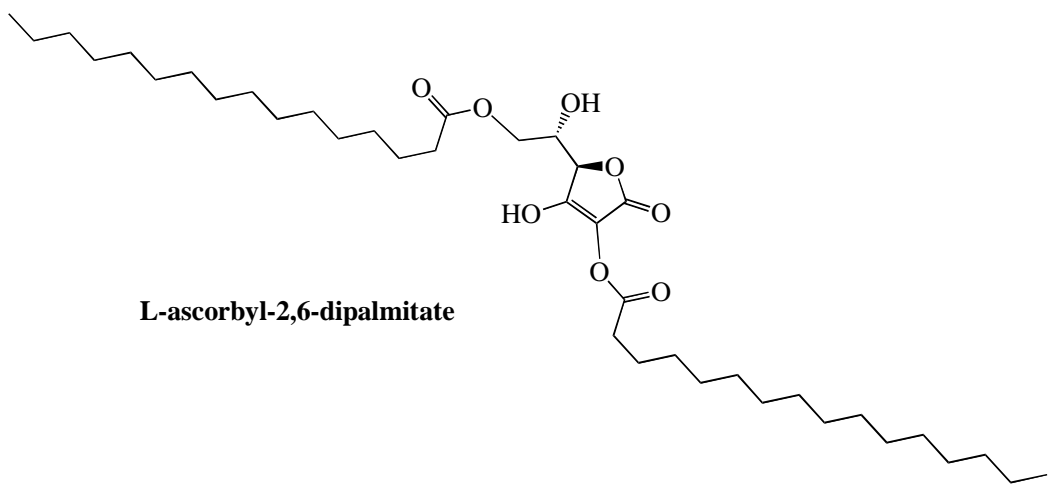

Fig. (3). Commercial derivatives of L-ascorbic acid.

slower (Fig. 4). When using vinyl palmitate, the reaction yields vinyl alcohol as leaving group, which rapidly tautomerises to acetaldehyde and can be removed by evaporation as its boiling point is only $21^{\circ} \mathrm{C}$, thus displacing the equilibrium and making the reaction completely irreversible [39]. Although good yields and conversions have been achieved using the lipase B from $C$. antarctica, these processes have not been adopted by the industry.

Other vitamin $\mathrm{C}$ derivatives are commercially available (Fig. 3). The novel vitamin $\mathrm{C}$ derivative, 2-O- $\alpha-\mathrm{D}-$ glucopyranosyl-L-ascorbic acid (ascorbic acid 2-glucoside) is synthesised enzymatically $[33,50]$ and its biological activity has been evaluated in vitro and in vivo [51]. The stability of the other transglycosylated ascorbic acid derivatives, such as 6- $O$-alpha-D-glucosyl- and 6- $O$-alpha-D-maltosylascorbic acid, was greatly enhanced against in vitro oxidation. The antioxidant effects of glycosyl-derivatives of ascorbic acid on the lipid oxidation in cooked chicken breast meat patties indicated that they had antioxidant activities similar to that of ascorbic acid [52]. It was suggested that the transglycosylated ascorbic acids can possibly be applied as effective antioxidants with improved stability in food, cosmetic, and other applications [53,54]. L-ascorbyl phosphate (magnesium salt) is very stable in creams and lotions, and is readily absorbed through the skin (Fig. 3). After absorption, it is quickly hydrolysed to vitamin $\mathrm{C}$, which suppresses the skin pigmentation action by melanin. Ascorbyl 2,6-palmitate (Fig. 3) is also marketed [55]; it is an stable agent that is applied as anti-stress agent for animals in feed compositions [56].

\section{STABILIZATION OF TOCOPHEROLS (VITAMIN E)}

Among the natural antioxidants, the term vitamin E describes the beneficial biological activity on humans of a group of structurally related compounds, in particular $\alpha, \beta$, $\gamma$ and $\delta$-tocopherol, and $\alpha, \beta, \gamma$ and $\delta$-tocotrienol [30]. Vitamin $E$ enhances the resistance to oxidation of the organisms, owing to its ability to protect polyunsaturated fatty acids 
Table 2. Enzymatic Synthesis of Fatty Acid Derivatives of L-Ascorbic Acid

\begin{tabular}{|c|c|c|c|c|}
\hline Methyl palmitate & $2 \mathrm{M} 2 \mathrm{~B}^{\mathrm{a}}$ & Novozym $435^{\mathrm{b}}$ & 68 & [31] \\
\hline $\begin{array}{c}\text { Methyl palmitate, } \\
\text { EPA and DHA ethyl esters }\end{array}$ & 2M2B & Novozym 435 & $\leq 40$ & [41] \\
\hline Vinyl esters (C8-C16) & $t$-butanol & Chyrazyme L-2 ${ }^{\mathrm{b}}$ & $\leq 91$ & [32] \\
\hline Palmitic acid & Hexane & $\begin{array}{l}\text { Lipase from Bacillus } \\
\text { stearo-thermophilus }\end{array}$ & $\leq 97$ & [43] \\
\hline $\mathrm{EPA}^{\mathrm{d}}$ & Acetone & Chyrazyme L-2 & 47 & [44] \\
\hline $\begin{array}{l}\text { Saturated fatty acids } \\
\qquad(\mathrm{C} 10-\mathrm{C} 14)\end{array}$ & Acetone & Chyrazyme L-2 & $\leq 60$ & [47] \\
\hline $\begin{array}{c}\text { Oleic acid, } \\
\text { Linoleic acid, } \\
\text { Linolenic acid }\end{array}$ & Acetone & Chyrazyme L-2 & 60 & [48] \\
\hline Oleic acid & Ionic liquid & Novozym 435 & 61 & [49] \\
\hline $\begin{array}{c}\text { Oleic acid, } \\
\text { Linoleic acid }\end{array}$ & $2 \mathrm{M} 2 \mathrm{~B}$ & Novozym 435 & $\leq 45$ & [29] \\
\hline
\end{tabular}

a 2-methyl-2-butanol ( $t$-amyl alcohol).

${ }^{\mathrm{b}}$ Different immobilised preparations of lipase B from C. antarctica.

'2-methyl-2-pentanol.

${ }^{\mathrm{d}}$ EPA: eicosapentaenoic acid; DHA: docosahexaenoic acid.

from peroxidation and to scavenge free radicals. It is a primary antioxidant as it terminates the free radical chains in lipid oxidation [26]. Vitamin $\mathrm{E}$ has an important presence in the animal nutrition market, where high doses of this antioxidant are applied to improve the quality and shelf-life of meat [30].

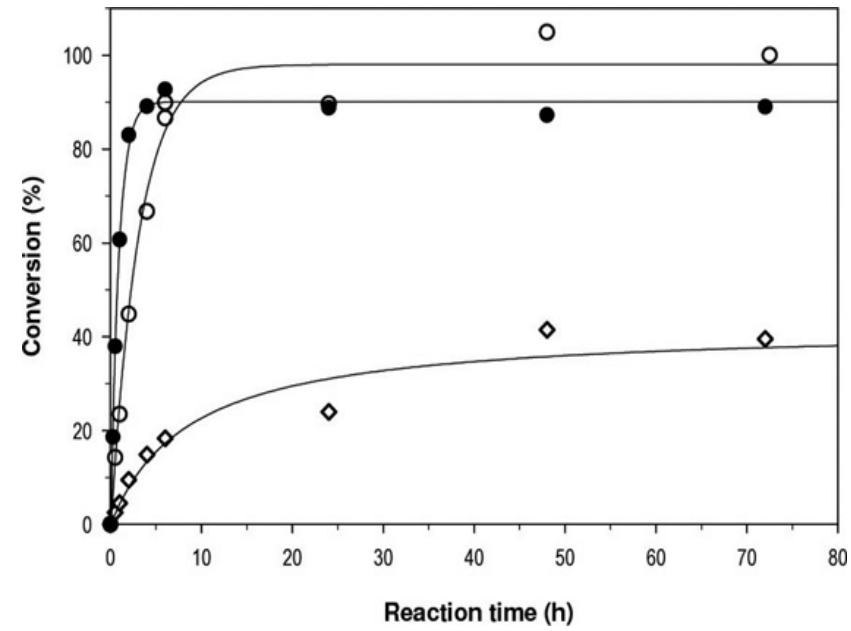

Fig. (4). Time-course of ascorbyl palmitate synthesis by transesterification of vinyl palmitate and L-ascorbic acid catalysed by: (०) Novozym 435; $(\bullet)$ C. antarctica lipase B adsorbed on Accurel. $(\diamond)$ Transesterification of ethyl palmitate and L-ascorbic acid catalysed by Novozym 435 .
The tocopherols are characterised by the 6-chromanol ring structure methylated to varying degrees at the 5,7 and 8 position (Fig. 5). At the position 2, there is a $\mathrm{C} 16$ saturated side chain that has no effect on its antioxidant activity but serves to insert and hold the chemically reactive "head" in biomembranes [57]. Tocotrienols are unsaturated at the 3', 7' and 11' positions of the side chain. Tocopherols have three chiral centers at carbons 2, 4'- and 8'- (Fig. 5), and the naturally occurring isomers have the RRR-configuration [58]. It seems to exist a structure-function relationship in vitamin E. Birringer et al. [44] explained that tocopherols have three different domains: functional one, responsible of the antioxidant activity; signalling one, regulator of the protein kinase $\mathrm{C}$; and the hydrophobic one, analogue in biological membranes and lipoproteins.

Considering the so-called "vitamin E activity", which is related with gene expression and regulation, apoptosis, and signal transduction, there is agreement that the RRR- $\alpha$ tocopherol is the most bioactive compound $[59,60]$ as it is specifically recognised by membranes [11]. Thus, the isomer with inverted stereochemistry at position 2 has only $30 \%$ of the biological activity of the RRR. Attempts are being made to develop an efficient and stereocontrolled synthesis of the natural form of $\alpha$-tocopherol [61]. In contrast, the antioxidant activity of tocopherols is in the order of $\delta>\gamma>\beta>\alpha$. The antioxidant activity of tocotrienols generally exceeds those of tocopherols. 

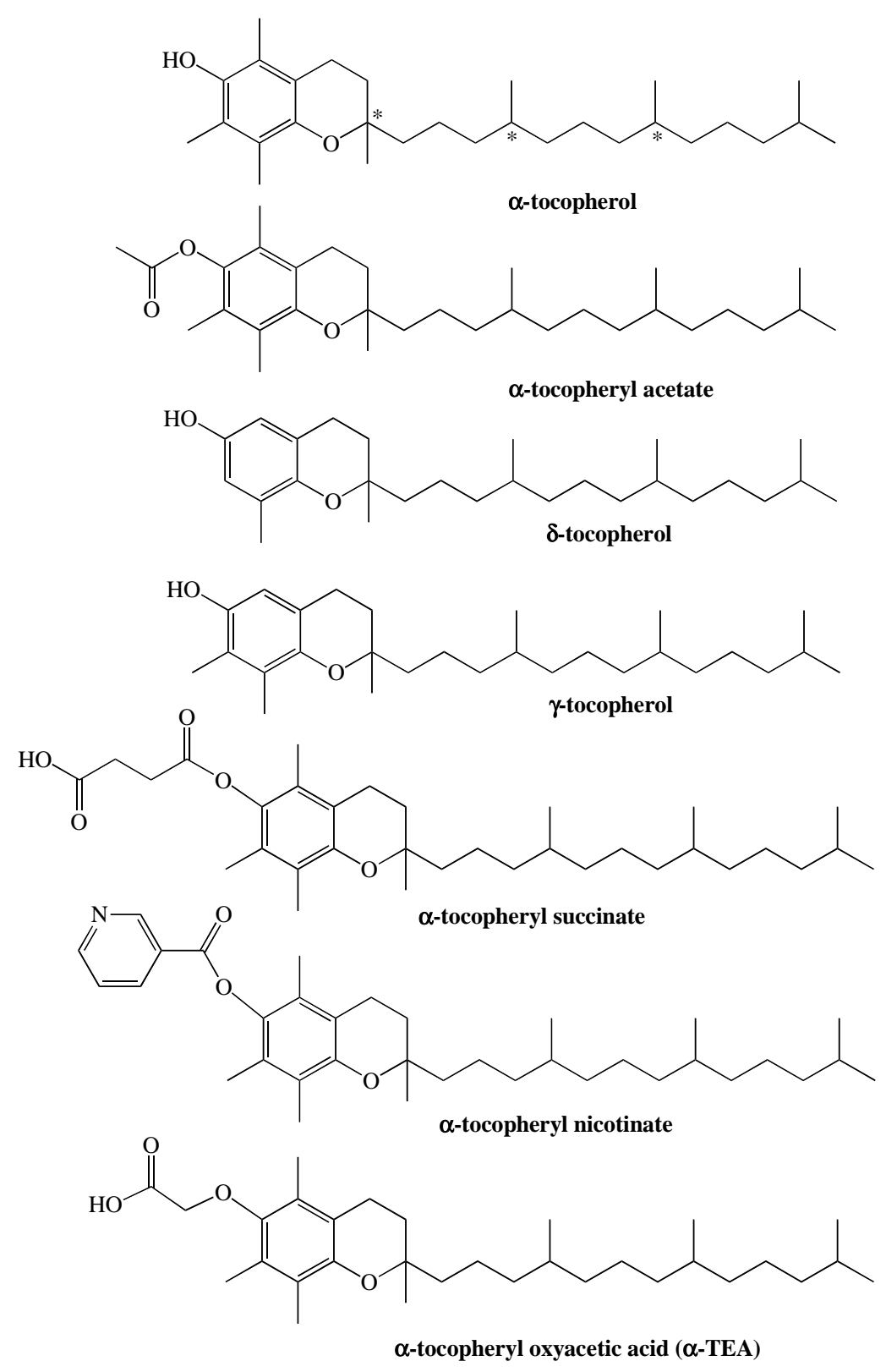

Fig. (5). Structure of $\alpha$-tocopherol (the location of the three chiral centers is marked with an asterisk) and its commercial derivatives.

Different forms of vitamin $\mathrm{E}$ are marketed: RRR- $\alpha-$ tocopherol, pure (all-rac)- $\alpha$-tocopherol, mixed tocopherols having various contents of $\alpha$-, $\gamma$ - and $\delta$-derivatives, vitamin E esters (acetate, succinate or nicotinate) and ethers ( $\alpha$-TEA) (Fig. 5). Commercially available RRR- $\alpha$-tocopherol is derived from deodorizer distillate, a by-product of soybean oil refining process. The synthetic vitamin $\mathrm{E}$ ( $\alpha$-tocopherol) is obtained by reaction of trimethylhydroquinone with isophytol [62], without any control of stereochemistry, and consists of eight stereoisomers in equal proportions (RRR, RRS, RSR, RSS, SSS, SRR, SRS, SSR) designated all racemic (all-rac)- $\alpha$-tocopherol [60]. Although (all rac)- $\alpha$-tocopherol is not as biologically active as the natural RRR stereoisomer [63], the production volume is above $1000 \mathrm{t}$ per annum [64].

In order to develop novel antioxidants better than vitamin $\mathrm{E}$, several attempts to synthesize vitamin $\mathrm{E}$ analogs have been reported [57]. Vitamin E is generally administered as a prodrug in the form of all-rac- $\alpha$-tocopheryl acetate (vitamin
E acetate) or all-rac- $\alpha$-tocopheryl succinate (Fig. 5). Vitamin E acetate carries an acetyl moiety at the C- 6 phenolic group to increase its stability in the presence of light and oxygen, but this modification blocks the antioxidant properties [65]. For this reason, vitamin $\mathrm{E}$ acetate is not suitable for use as antioxidant in lipids and lipid-containing foods. However, vitamin $\mathrm{E}$ acetate is added to foods to increase vitamin $\mathrm{E}$ content because the shelf life of vitamin $\mathrm{E}$ acetate is greater than that of the unesterified tocopherol [66]. In vivo, unspecific esterases rapidly cleave the ester bond and release the active $\alpha$-tocopherol. Tocopheryl acetate is the major sales form of vitamin E, both in the human [67] and animal [68] nutrition markets. Vitamin $\mathrm{E}$ acetate is so versatile that has even been patented for use in liquid dish cleaning compositions [69].

The vitamin E acetate is synthesised by chemical acylation with acetic acid or acetic anhydride using different acid or base catalysts such as sulphuric acid or pyridine [70,71]. 


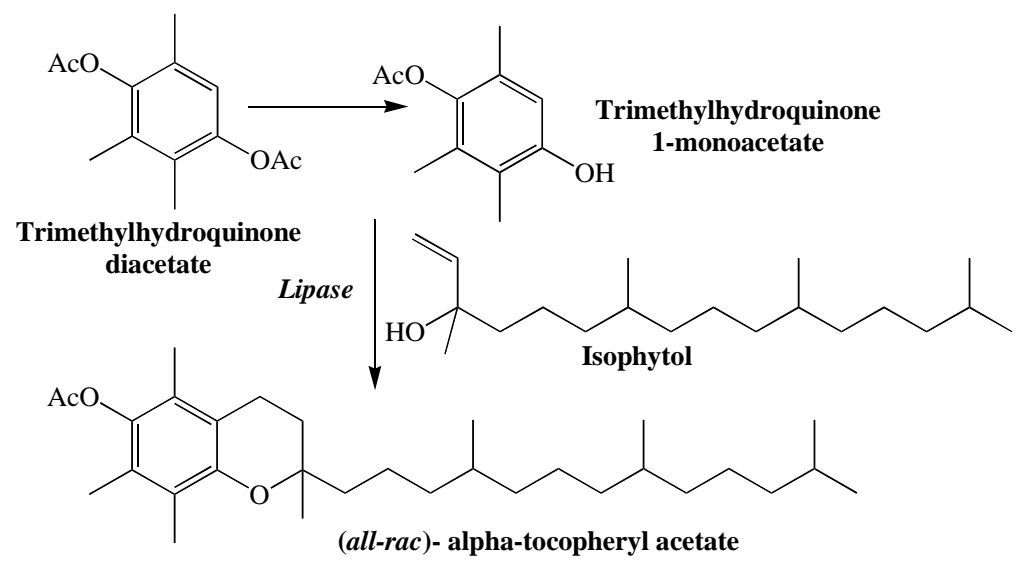

Fig. (6). Chemoenzymatic process for the synthesis of vitamin E acetate.

Several continuous or discontinuous processes have been described [64]. We recently described for the first time the enzymatic acetylation of vitamin E [37,72]. Out of 15 lipases, esterases and proteases screened, only the lipase B from $C$. antarctica catalysed the acylation. The acetylation of $\delta$-tocopherol was faster than that of $\alpha$-tocopherol, probably due to its lower methylation degree. By computational conformation studies, it has been demonstrated that the acceptor binding site of lipase B from C. antarctica is deep (compared with other lipases, e.g. that from Thermomyces lanuginosus) [73], which partly explains the broader specificity of C. antarctica lipase B $[74,75]$.

An alternative route to all-rac- $\alpha$-tocopheryl acetate is the reaction of trimethyl-hydroquinone-1-monoacetate with isophytol (Fig. 6) [76]. The diacetate is easy to obtain in large amounts from cheap $\alpha$-isophorone; however, the selective hydrolysis to 1-monoacetate is difficult to achieve by standard chemical methods. As an alternative, the lipasecatalysed hydrolysis has been reported [76]. Lipase from $T$. lanuginosus (formerly Humicola lanuginosa) hydrolysed regioselectively the diacetate in water-saturated $t$-butyl methyl ether [76]. This lipase is inexpensive as it is used as an additive for detergents. Its immobilization on polypropylene enhanced activity without affecting regioselectivity. Neither monoacetate isomer nor hydroquinone (the product of total hydrolysis) were detected making this process superior to chemical deacetylation [77].

With the aim to improve the stability to light and the solubility in water, other analogues have been synthesised using amino acids such as glycine, alanine and pyroglutamic acid. These compounds have the advantage that the hydrolysis produces not only $\alpha$-tocopherol, but also nutritional components, to obtain a synergic effect [60]. In addition, $\alpha-$ tocopheryl nicotinate (Fig. 5) has shown antiarrhythmic activity and is used in Europe and Japan as a lipid-lowering agent. Other new application of vitamin E is as antiproliferative agent in different kinds of cancer. In this context, a novel vitamin $\mathrm{E}$ analogue was synthesised by Lawson $e t$ al. [61] that contains a nonhydrolyzable ether linked acetic acid $(\alpha$-TEA).

In this context, a glucosyl derivative of vitamin $\mathrm{E}$ has also been synthesised enzymatically from 2-hydroxymethyl2,5,7,8-tetramethylchroman-6-ol and maltose by transglyco- sylation with $\alpha$-glucosidase from Saccharomyces species [78].

\section{CONCLUSIONS}

Antioxidants are increasingly important additives in food processing. As well as their traditional role in inhibiting the development of oxidative rancidity in fat-based foods, particularly meat and dairy products and fried foods, more recent research has suggested a new role in inhibiting cardiovascular disease and cancer. Stabilization of antioxidant vitamins for food and feed applications is a critical step to expand their range of applications.

\section{ACKNOWLEDGEMENTS}

We thank Ana V. Ugidos and Soledad Peña (Biotecnologías Aplicadas, BTSA, Spain) for technical information and suggestions. This research was supported by the Spanish CSIC (Project 200680F0132), Spanish MEC (Projects BIO2002-00337 and BIO2007-67708-C04-01) and European Union (Project MIF1-CT-2006-040163). Spanish MEC and Comunidad de Madrid are also thanked for fellowships to Dr. A. Kunamneni (SB2004-0011) and P. Torres, respectively.

\section{REFERENCES}

[1] Fang YZ, Yang S, Wu GY. Free radicals, antioxidants, and nutrition. Nutrition 2002; 18: 872-879.

[2] Calabrese V, Maines MD. Antiaging medicine: Antioxidants and aging. Antiox Redox Signal 2006; 8: 362-364.

[3] Johnson IT. Antioxidants and antitumour properties. In: Pokorny J, Yanishlieva N, Gordon M, eds. Antioxidants in food: Practical applications. Cambridge: CRC Press, 2001: 100-123.

[4] Mantovani G, Maccio A, Madeddu C, et al. The impact of different antioxidant agents alone or in combination on reactive oxygen species, antioxidant enzymes and cytokines in a series of advanced cancer patients at different sites: Correlation with disease progression. Free Radic Res 2003; 37: 213-223.

[5] Siekmeier R, Steffen C, Maerz W. Role of oxidants and antioxidants in atherosclerosis: Results of in vitro and in vivo investigations. J Cardiovasc Pharm Therap 2007; 12: 265-282.

[6] Spence JD. Nutrition and stroke prevention. Stroke 2006; 37: 24302435.

[7] Firuzi O, Fuksa L, Spadaro C, et al. Oxidative stress parameters in different systemic rheumatic diseases. J Pharm Pharmacol 2006; 58: 951-957.

[8] Droge W, Schipper HM. Oxidative stress and aberrant signaling in aging and cognitive decline. Aging Cell 2007; 6: 361-370. 
[9] Geronikaki AA, Gavalas AM. Antioxidants and inflammatory disease: Synthetic and natural antioxidants with anti-inflammatory activity. Comb Chem High T Scr 2006; 9: 425-442.

[10] Rahimi R, Nikfar S, Larijani B, Abdollahi M. A review on the role of antioxidants in the management of diabetes and its complications. Biomed Pharmacother 2005; 59: 365-373.

[11] Cerecetto H, Lopez GV. Antioxidants derived from vitamin E: An overview. Mini Rev Med Chem 2007; 7: 315-338.

[12] Roberfroid MB. Functional foods: concepts and application to inulin and oligofructose. Br J Nutr 2002; 87: S139-43.

[13] Wiseman A, Woods L. Addition of designer enhancers to functional foods: need also for redesigned biocatalysts in fail-clean strategies of bioprocessing?. J Chem Technol Biotechnol 2001; 76 : 1038-1040.

[14] Pokorny J. Introduction. In: Pokorny J, Yanishlieva N, Gordon M, eds. Antioxidants in food: Practical applications. Cambridge: CRC Press, 2001: 1-3.

[15] Gordon MH. The development of oxidative rancidity in foods. In: Pokorny J, Yanishlieva N, Gordon M, eds. Antioxidants in food: Practical applications. Cambridge: CRC Press, 2001: 7-21.

[16] Kochhar SP. Stabilisation of frying oils with natural antioxidative components. Eur J Lipid Sci Technol 2000; 102: 552-559.

[17] Safari M, Karboune S, St Louis R, Kermasha S. Enzymatic synthesis of structured phenolic lipids by incorporation of selected phenolic acids into triolein. Biocatal Biotransfor 2006; 24: 272-279.

[18] Stamatis H, Sereti V, Kolisis FN. Enzymatic synthesis of hydrophilic and hydrophobic derivatives of natural phenolic acids in organic media. J Mol Catal B-Enzyme 2001; 11: 323-328.

[19] Netscher T, Bonrath W, Haas A, Hoppmann E, Pauling H. Polyfluorinated strong bronsted acids as efficient catalysts in vitamin $\mathrm{E}$ chemistry. Proceedings of the 13th European Symposium on Organic Chemistry; 2003: Cavtat Dubrovnik, Croatia; 2003; pp. 43-6.

[20] Lenardao EJ, Freitag RA, Dabdoub MJ, Batista ACF, Silveira CD. Green chemistry - The 12 principles of green chemistry and it insertion in the teach and research activities. Quimica Nova 2003; 26: 123-129.

[21] Sheldon RA, van Rantwijk F. Biocatalysis for sustainable organic synthesis. Aust J Chem 2004; 57: 281-289.

[22] Alcalde M, Ferrer M, Plou FJ, Ballesteros A. Environmental biocatalysis: from remediation with enzymes to novel green processes. Trends Biotechnol 2006; 24: 281-287.

[23] Azerad R. Chemical biotechnology - Better enzymes for green chemistry - Editorial overview. Curr Opin Biotechnol 2001; 12: 533-534.

[24] Ferrer M, Beloqui A, Golyshin PN. Microbial metagenomes: moving forward industrial biotechnology. J Chem Technol Biotechnol 2007; 82: 421-423.

[25] Zumarraga M, Plou FJ, Garcia-Arellano H, Ballesteros A, Alcalde M. Bioremediation of polycyclic aromatic hydrocarbons by fungal laccases engineered by directed evolution. Biocatal Biotransfor 2007; 25: 219-228.

[26] Kochhar SP, Rossell JB. Detection, estimation and evaluation of antioxidants in food systems. In: Hudson BJF, ed. Food Antioxidants. 1st ed. Essex, England: Elsevier Science Publishers LTD, 1990:19-64.

[27] Noguchi N, Watanabe A, Shi HL. Diverse functions of antioxidants. Free Radic Res 2000; 33: 809-817.

[28] LoNostro P, Capuzzi G, Pinelli P, Mulinacci N, Romani A, Vincieri FF. Self-assembling and antioxidant activity of some vitamin C derivatives. Colloid Surf A-Physicochem Eng Asp 2000; 167: 83-93.

[29] Song QX, Wei DZ, Zhou WY, Xu WQ, Yang SL. Enzymatic synthesis and antioxidant properties of L-ascorbyl oleate and Lascorbyl linoleate. Biotechnol Lett 2004; 26: 1777-1780.

[30] Valentin HE, Qi QG. Biotechnological production and application of vitamin E: current state and prospects. Appl Microbiol Biotechnol 2005; 68: 436-444.

[31] Humeau C, Girardin M, Coulon D, Miclo A. Synthesis of 6-Opalmitoyl L-ascorbic-acid catalyzed by Candida antarctica lipase. Biotechnol Lett 1995; 17: 1091-1094.

[32] Yan YC, Bornscheuer UT, Schmid RD. Lipase-catalyzed synthesis of vitamin C fatty acid esters. Biotechnol Lett 1999; 21: 10511054.

[33] Jun HK, Bae KM, Kim YH. Identification of L-ascorbic acid 2-Oalpha-glucoside, a stable form of ascorbic acid, in kimchi. J Microbiol Biotechnol 1998; 8: 710-713.
[34] Song QX, Wei DZ. Study of vitamin C ester synthesis by immobilized lipase from Candida sp. J Mol Catal B-Enzyme 2002; 18: 261-266.

[35] Arcos JA, Bernabe M, Otero C. Quantitative enzymatic production of 6-O-acylglucose esters. Biotechnol Bioeng 1998; 57: 505-509.

[36] Park S, Viklund F, Hult K, Kazlauskas RJ. Ionic liquids create new opportunities for nonaqueous biocatalysis with polar substrates: Acylation of glucose and ascorbic acid. Ionic Liquids As Green Solvents: Progress and Prospects. ACS Symposium Series 2003; 856: $225-238$.

[37] Torres P, Lopez-Cortes N, Reyes-Duarte D, Plou FJ, Ballesteros A. Acylation of antioxidant vitamins $\mathrm{C}$ and $\mathrm{E}$ using immobilized lipases: 2007. Proceedings of the 8th International Symposium on Biocatalysis and Biotransformations, Biotrans 2007; 8-13; Oviedo, Spain; 2007; p. 191.

[38] Lopez-Cortes N, Torres P, Beloqui A, et al. An alternative to the chemical modification of antioxidant vitamins using commercial and novel enzymes from extreme metagenomes: 2006. Proceedings of the International Symposium on Environmental Biocatalysis: From remediation with enzymes to novel green processes; Apr 2326; Cordoba, Spain; 2006, p. 62.

[39] Reyes-Duarte D, Lopez-Cortes N, Ferrer M, Plou FJ, Ballesteros A. Parameters affecting productivity in the lipase-catalysed synthesis of sucrose palmitate. Biocatal Biotransfor 2005; 23: 19-27.

[40] Otto RT, Bornscheuer UT, Scheib H, Pleiss J, Syldatk C, Schmid RD. Lipase-catalyzed esterification of unusual substrates: Synthesis of glucuronic acid and ascorbic acid (vitamin C) esters. Biotechnol Lett 1998; 20: 1091-1094.

[41] Humeau C, Girardin M, Rovel B, Miclo A. Enzymatic synthesis of fatty acid ascorbyl esters. J Mol Catal B-Enzyme 1998; 5: 19-23.

[42] Stamatis H, Sereti V, Kolisis FN. Studies on the enzymatic synthesis of lipophilic derivatives of natural antioxidants. J Am Oil Chem Soc 1999; 76: 1505-1510.

[43] Bradoo S, Saxena RK, Gupta R. High yields of ascorbyl palmitate by thermostable lipase-mediated esterification. J Am Oil Chem Soc 1999; 76: 1291-1295.

[44] Watanabe Y, Minemoto Y, Adachi S, Nakanishi K, Shimada Y, Matsuno R. Lipase-catalyzed synthesis of 6-O-eicosapentaenoyl Lascorbate in acetone and its autoxidation. Biotechnol Lett 2000; 22 : 637-640.

[45] Maugard T, Tudella J, Legoy MD. Study of vitamin ester synthesis by lipase-catalyzed transesterification in organic media. Biotechnol Progr 2000; 16: 358-362.

[46] Viklund F, Alander J, Hult K. Antioxidative properties and enzymatic synthesis of ascorbyl FA esters. J Am Oil Chem Soc 2003; 80: 795-799.

[47] Watanabe Y, Kuwabara K, Adachi S, Nakanishi K, Matsuno R. Production of saturated acyl L-ascorbate by immobilized lipase using a continuous stirred tank reactor. J Agric Food Chem 2003; 51: 4628-4632.

[48] Kuwabara K, Watanabe Y, Adachi S, Nakanishi K, Matsuno R. Synthesis of 6-O-unsaturated acyl L-ascorbates by immobilized lipase in acetone in the presence of molecular sieve. Biochem Eng $\mathbf{J}$ 2003; 16: 17-22.

[49] Park S, Viklund F, Hult K, Kazlauskas RJ. Vacuum-driven lipasecatalysed direct condensation of L-ascorbic acid and fatty acids in ionic liquids: synthesis of a natural surface active antioxidant. Green Chem 2003; 5: 715-719.

[50] Aga H, Yoneyama M, Sakai S, Yamamoto I. synthesis of 2-Oalpha-D-glucopyranosyl L-ascorbic acid by cyclomaltodextrin glucanotransferase from Bacillus stearothermophilus. Agr Biol Chem 1991; 55: 1751-1756.

[51] Kumano Y, Sakamoto T, Egawa M, Iwai I, Tanaka M, Yamamoto I. In vitro and in vivo prolonged biological activities of novel vitamin $\mathrm{C}$ derivative, 2-O-alpha-D-glucopyranosyl-L-ascorbic acid (AA-2G), in cosmetic fields. J Nutr Sci Vitaminol 1998; 44: 345359 .

[52] Bae HK, Lee SB, Park CS, et al. Modification of ascorbic acid using transglycosylation activity of Bacillus stearothermophilus maltogenic amylase to enhance its oxidative stability. J Agric Food Chem 2002; 50: 3309-3316.

[53] Jun HK, Bae KM, Kim SK. Production of 2-O-alpha-Dglucopyranosyl L-ascorbic acid using cyclodextrin glucanotransferase from Paenibacillus sp. Biotechnol Lett 2001; 23: 1793-1797.

[54] Lee SB, Nam KC, Lee SJ, Lee JH, Inouye K, Park KH. Antioxidative effects of glycosyl-ascorbic acids synthesized by maltogenic 
amylase to reduce lipid oxidation and volatiles - Production in cooked chicken meat. Biosci Biotechnol Biochem 2004; 68: 36-43.

[55] Fujinami Y, Tai A, Yamamoto I. Radical scavenging activity against 1,1-diphenyl-2-picrylhydrazyl of ascorbic acid 2-glucoside (AA-2G) and 6-acyl-AA-2G. Chem Pharm Bull 2001; 49: 642-644.

[56] Ito S, Ogata E, Yamada M. Anti-stress agent for animals and a method of reducing stress in animals. United States patent US 5937790. 1999 Aug.

[57] Chen WJ, Song JR, Guo P, Cao W, Bian J. Exploring a possible way to synthesize novel better antioxidants based on vitamin E: A DFT study. Bioorg Med Chem Lett 2006; 16: 5874-5877.

[58] Weiser H, Vecchi M, Schlachter M. Stereoisomers of alphatocopheryl acetate. 4. USP units and alpha-tocopherol equivalents of all-rac-tocopherol, 2-ambo-tocopherol and RRR-alphatocopherol evaluated by simultaneous determination of resorptiongestation, myopathy and liver-storage capacity in rats. Int J Vitam Nutr Res 1986; 56: 45-56.

[59] Lang JK, Schillaci M, Irvin B. Vitamin E. In: De Leenheer AP, Lambert WE, Nelis HJ, eds. Modern chromatographic analysis of vitamins. New York: Marcel Dekker, Inc.; 1992: 153-95.

[60] Lodge JK. Vitamin E bioavailability in humans. J Plant Physiol 2005; 162: 790-796.

[61] Nozawa M, Takahashi K, Kato K, Akita H. Enantioselective synthesis of $\left(2 \mathrm{R}, 4^{\prime} \mathrm{R}, 8^{\prime} \mathrm{R}\right)$-alpha-tocopherol (vitamin $\left.\mathrm{E}\right)$ based on enzymatic function. Chem Pharm Bull 2000; 48: 272-277.

[62] Bonrath W, Haas A, Hoppmann E, et al. Synthesis of (all-rac)alpha-tocopherol using fluorinated $\mathrm{NH}$-acidic catalysts. Adv Synth Catal 2002; 344: 37-39.

[63] Brigelius-Flohe R, Traber MG. Vitamin E: function and metabolism. FASEB J 1999; 13: 1145-1155.

[64] Bonrath W, Netscher T. Catalytic processes in vitamins synthesis and production. Appl Catal A-Gen 2005; 280: 55-73.

[65] Schneider C. Chemistry and biology of vitamin E. Mol Nutrit Food Res 2005; 49: 7-30.

[66] Cho IK, Rima J, Chang CL, Li QX. Spectrofluorometric and highperformance liquid chromatographic determination of all-racalpha-tocopheryl acetate in virgin olive oil. J Food Composit Anal 2007;20:57-62.

[67] WinklhoferRoob BM, vantHof MA, Shmerling DH. Long-term oral vitamin E supplementation in cystic fibrosis patients: RRR-alphatocopherol compared with all-rac-alpha-tocopheryl acetate preparations. Am J Clin Nutr 1996;63:722-728.
[68] Ozkan S, Malayoglu HB, Yalcin S, et al. Dietary vitamin E (alphatocopherol acetate) and selenium supplementation from different sources: performance, ascites-related variables and antioxidant status in broilers reared at low and optimum temperatures. Brit Poultry Sci 2007; 48: 580-593.

[69] Suriano DF, Exarchakis J, Arvanitidou P. Liquid dish cleaning compositions containing vitamin E acetate. United States patent US 20050019293. 2005 Jan.

[70] Netscher T. Synthesis and production of vitamin E. In: Gunstone FD, ed. Lipid Synthesis and Manufacture. Sheffield, UK: Sheffield Academic Press Ltd.; 1999: 250-67.

[71] Bonrath W, Giraudi, L. Process for the manufacture of tocyl and tocopheryl acylates. World Patent WO 2004096791. 2004 Nov.

[72] Torres P, Reyes-Duarte D, Lopez-Cortes N, Ferrer M, Ballesteros A, Plou FJ. Acetylation of vitamin E by Candida antarctica lipase B immobilized on different carriers. Process Biochem 2008; 43: 145-153.

[73] Pleiss J, Fischer M, Schmid RD. Anatomy of lipase binding sites: the scissile fatty acid binding site. Chem Phys Lipids 1998; 93: 6780 .

[74] Uppenberg J, Ohrner N, Norin M, et al. Crystallographic and molecular-modeling studies of lipase B from Candida antarctica reveal a stereospecificity pocket for secondary alcohols. Biochemistry-US 1995; 34: 16838-16851.

[75] Fuentes G, Ballesteros A, Verma CS. Specificity in lipases: A computational study of transesterification of sucrose. Protein Sci 2004; 13: 3092-3103.

[76] Bonrath W, Karge R, Netscher T. Lipase-catalyzed transformations as key-steps in the large-scale preparation of vitamins. J Mol Catal B-Enzym 2002; 19-20: 67-72.

[77] Bonrath W, Eisenkrätzer D, Enjolras V, Karge R, Netscher T, Schneider M. Conversion of trimethylhydroquinone diacetate into trimethylhydroquinone-1-monoacetate, by subjecting trimethylhydroquinone diacetate to monosaponification by lipase, for producing (all-rac)-alpha-tocopherol/its acetate. European patent EP 1239045. 2002 Sept.

[78] Murase H, Yamauchi R, Kato K, Kunieda T, Terao J. Synthesis of a novel vitamin E derivative, 2-(alpha-D-glucopyranosyl)methyl2,5,7,8-tetramethylchroman-6-ol, by alpha-glucosidase-catalyzed transglycosylation. Lipids 1997; 32: 73-78. 